\title{
Commentary On Wayne and McCosh (2018): "Diversity as a Problematic Predictor of Organizational Performance: Issues of Context and Expectations"
}

\author{
BANU OZKAZANC-PAN \\ Corresponding author: Banu.ozkazanc-pan@umb.edu \\ University of Massachusetts, Boston, USA and Brown University, USA
}

In their article, Wayne and McCosh (2018) problematize uncritical ways in which diversity research has studied the link between extant diversity variables and organizational performance. They point out that researchers may be overpromising the benefits of diversity while not addressing the critical tensions that arise in organizational settings due to diversity. Further, they suggest that there is little standardization in the field around not only the definition of diversity or its conceptualization but also around which variables and concepts are used in studies. As a consequence, studies that study 'diversity' and its potential impact on various dimensions of organizational performance suffer from a lack of precision, replicability, and generalizability. As Wayne and McCosh (2018) contend, the central issue is around how diversity is defined, multiple different variables that are used to represent facets of diversity and scholarly interest in making the business case for diversity. To address these shortcomings, the authors instead call for a more nuanced and context-specific approach to the study of diversity and its potential to impact organizational performance. Their approach is to borrow from Hofstede's (1988) work on cultural frameworks to query complex organizational phenomenon related to diversity.

Their work arrives in a long line of research around the topic of diversity. In fact, questions and concerns about diversity have a long-standing tradition in management and organization studies and date back to the time of the influential Johnston and Packer (1987) Workforce 2000 report. The influence of this report, which outlined the changing demographic nature of the workforce in the coming years, was to bring attention to the fact that that the growing number of women and non-Whites entering the workforce was most likely to have an impact on organizations and workplaces. At the same time, research around diversity was also influenced by earlier movements that emphasized equal rights and opportunities for traditionally marginalized populations in the U.S., such as the Civil Rights and Women's Rights movements of the 1960's (see Konrad, 2003). In earlier years, the focus on social justice as the prevailing ways in which diversity was studied gave way to later approaches that focused on the "business case" for 
diversity given that this provides much more traction with the corporate sector (Robinson and Dechant, 1997).

While notwithstanding the complexity of the issue, there have been positive linkages that have been reported in research examining the relationship between diversity and performance. As one example, Herring found that "racial diversity is associated with increased sales revenue, more customers, greater market share, and greater relative profits. Gender diversity is associated with increased sales revenue, more customers, and greater relative profits" (2009: 208). Thus, clarity around which dimensions of diversity lead to potentially positive performance outcomes is important in assessing the relative value of diversity in organizational contexts.

In recent years and in line with Wayne and McCosh's (2018) reasoning, scholars have begun to provide much more nuanced approaches to the linkages between diversity and organizational performance. A recent meta-analysis by Hoobler et al. (2018) provides even further details and complexity to the relationship between diversity and performance. They note, "commonly used methods of testing the business case for women leaders may limit our ability as scholars to understand the value that women bring to leadership positions. We do not advocate that the business case be abandoned altogether but, rather, improved and refined. We name exemplary research studies to show how different perspectives on gender, alternative conceptualizations of value, and the specification of underlying mechanisms linking leadership to performance can generate changes in both the dominant ontology and the epistemology underlying this body of research" (Hoobler et al., 2018: 2473).

It is in this vein that the work of Wayne and McCosh (2018) starts an important conversation about the ways in which diversity dimensions impact not on individual experiences but organizational outcomes generally, performance specifically. They state, "Pragmatically speaking, why should traditionally studied characteristics like gender, race, or ethnicity matter-especially within a common geo-national culture-with regard to performance. Are not most top-level managers intelligent, well-trained, qualified, ambitious, and politically savvy individuals-regardless of their gender, race, or ethnicity?" (Wayne and McCosh, 2018: 27).

Indeed, in a world free of gender and racial bias their claim has merit. But we do not live in such a world just yet and thus, diversity and its various elements provide ways for us to name, study, understand, and mitigate organizational practices and processes that contribute to unequal outcomes for women and minorities. Numerous studies in organizational contexts have outlined how and why gender and racial bias takes shape (see Correll, 2017 for an overview). Within this context, the question of whether or not diversity contributes positively to organizational performance is important but not sufficient to answer their poignant question. Rather, we need to understand that diversity has become a politicized concept based on assumptions that are somehow 'lowering the bar' and 'making exceptions' for women, minorities, and immigrants among other groups. These ideas are based on the assumption that existing organizational practices including those related to diversity are merit-based rather than biased across gender, race or other diversity dimensions. Rather, research has demonstrated that pervasive cultural beliefs in the U.S. about gender, race and class impact how social relations take shape, which in turn create particular advantages or disadvantages for people who do not fit ascribed norms (Ridgeway and Kricheli-Katz, 2013).

Such social relations also have consequences for workplaces as they provide evidence that diversity dimensions impact how people are evaluated, compensated and promoted. Castilla (2015) demonstrates this very phenomenon in a study that examines pre and post-wage gaps in a longitudinal study of almost 9,000 employees in a private firm. His findings suggest that prior to, "introducing accountability and transparency into the company's performance-reward system $\cdots$ there was an observed gap in the distribution of performance-based rewards where women, ethnic minorities, and non-U.S.-born employees received lower monetary rewards compared with U.S.-born white men having the same performance evaluation scores and working in the same job and work unit with the same manager and the same 
human capital characteristics. Analyses of the company's employee performance-reward data after the adoption of accountability and transparency procedures show a reduction in this pay gap" (Castilla, 2015: 311).

To this end, organizational scholars are tasked with continuing research on diversity as it provides an important contribution to our understanding of workplaces and organizations and how different people may experience such spaces/places. Yet as Wayne and McCosh (2018) suggest, it is important to understand the contexts and nuanced ways in which diversity as a theoretical framework and set of social practices can lead to productive workplaces. As a final thought, researchers also need to be aware of their own biases in examining diversity given that our own identities and set of experiences may not allow us to appreciate or understand the experiences of others. These differences in workplace experiences should provide us with analytic rigor and contribute to our understanding of the complex issues at hand rather than divide scholars on which accounts are the most 'truthful' in relation to diversity. In all, the authors provide us with provocative and thoughtful insights around the topic of diversity and organizational performance-their work highlights that the politicized and impassioned nature of work on the topic may hinder our ability to truly understand diversity in different contexts. As we look to the future of research on this topic, collaborations between scholars of different disciplinary backgrounds stand to provide new insights and bring forth novel approaches and methods for conceptualizing and researching the complexity of diversity.

\section{References}

Castilla, E. J., 2015. Accounting for the Gap: A Firm Study Manipulating Organizational Accountability and Transparency in Pay Decisions. Organization Science, 26(2): 311-333.

Correll, S. J., 2017. SWS 2016 Feminist Lecture: Reducing Gender Biases in Modern Workplaces: A Small Wins Approach to Organizational Change. Gender \& Society, 31(6): 725-750.

Herring, C., 2009. Does Diversity Pay?: Race, Gender, and the Business Case for Diversity. American Sociological Review, $74(2), 208-224$.

Hoobler, J. M., Masterson, C. R., Nkomo, S. M. \& Michel, E. J., 2018. The Business Case for Women Leaders: Meta-analysis, Research Critique, and Path Forward. Journal of Management, 44(6): 2473-2499.

Johnston, W. B. \& Packer, A. E., 1987. Workforce 2000: Work and Workers for the 21st Century. Hudson Institute: Hudson, IN. Also available at http://files.eric.ed.gov/fulltext/ED290887.pdf

Konrad, A. M., 2003. Special Issue Introduction: Defining the Domain of Workplace Diversity Scholarship. Group 86 Organization Management, 28(1): 4-17.

Ridgeway, C. L. \& Kricheli-Katz, T., 2013. Intersecting Cultural Beliefs in Social Relations: Gender, Race, and Class Binds and Freedoms. Gender \& Society, 27(3): 294-318.

Robinson, G. \& Dechant, K., 1997. Building a Business Case for Diversity. Academy of Management Perspectives, 11(3), 21-31.

Wayne, K. T. \& McCosh, J. G., 2018. Diversity as a Problematic Predictor of Organizational Performance: Issues of Context and Expectations. Doing Business in an Interconnected World: Cross-Cultural Issues in Management and Marketing. Special Issue of the Journal of Management and Training for Industries. G.J. Kivenzor (Ed.). 